\title{
Fulminant Hepatitis A in Children, its Incidence, Presentation, Complications and Outcome: A Study from Eastern India
}

\author{
Mohanty N1', Mishra S², Panigrahi S³
}

\begin{abstract}
Introduction: Hepatitis A is one of the most frequent infectious liver diseases affecting children worldwide. The disease is usually mild and self-limited, and complications are very rare. But sometimes hepatitis $A$ can cause acute liver failure (ALF), a severe, life-threatening condition. The objective was to do clinicoepidemiological evaluation of hepatitis $A$ patients who were admitted to the In patients department of our hospital along with analyze the complications seen in the disease. Materials and Methods: It was a prospective study, done in Department of paediatrics, Maharaja Krushna Chandra Gajapati from May 2014-April 2016. Total number of patients was 80 . Patients having history or features of prodromal symptoms like fever, nausea, vomiting, anorexia, yellowish discoloration of urine and body, pain abdomen, change in mental status and coagulopathy with suspicion of acute hepatitis (within 8 wks) with positive IgM for hepatitis A were included in the group. Statistical analysis was done by SPSS software version 20. Results: Total number of patients was 80 .Mean age of hospitalisation was 5.5 years. $90 \%$ children were having jaundice. $85 \%$ patients were having liver enzyme high. Most common complication was gallbladder wall thickening followed by ascitis, pleural effusion etc. Encephalopathy was observed in three patients. Total three patients died. Maximum death was seen in infancy with delay in hospitalisation. Conclusions: Viral hepatitis due to hepatitis $A$ is a benign disease. But fulminant hepatic failure due to it is not uncommon. The lesser the age, presence of cardinal features like jaundice may not be apparent. So clinicians must be conscious of these lethal complications while managing a child of probable viral hepatitis. This study will raise the consciousness of urgency of vaccination for hepatitis $A$, which is thought to be sparingly optional for many parents as well as doctors.
\end{abstract}

Key words: Fulminant viral hepatitis, alanine transaminase, hepatitis A

\section{Introduction}

$\mathrm{H}$ epatitis $A$ is one of the most frequent infectious liver diseases affecting children worldwide. It is the commonest cause of viral
${ }^{1}$ Dr. Mohanty Niranjan, MBBS, MD, Professor and HOD, Department of Paediatrics, Maharaja Krishna Chandra Gajapati (MKCG) Medical College \& Hospital, Brahmapur, Odisha, India, ${ }^{2} \mathrm{Dr}$. Mishra Shubhankar, MBBS, MD, Senior Resident, Department of Paediatrics and Neonatology, Kalinga Institute of Medical Science, Bhubaneswar, Odisha, India, ${ }^{3} \mathrm{Dr}$. Panigrahi Sambedana, MBBS, Junior Resident, Department of Obstetrics and Gynaecology, Sriram Chandra Bhanj (SCB) Medical College \& Hospital, Cuttack, Odisha, India.

\section{Address for correspondence \\ Dr. Shubhankar Mishra, Senior Resident, Department of Paediatrics and Neonatology, Kalinga Institute of Medical Science, \\ Bhubaneswar, Odisha, India \\ Tel No; \\ E-mail: dr.subham.scb@gmail.com}

Acknowledgements: We would like to thank the department of paediatrics, MKCG Medical College, Berhampur, Odisha, India

Funding: Nil

Conflict of Interest: None

Permission from IRB: Yes

How to cite

Mohanty N, Mishra S, Panigrahi S. Fulminant Hepatitis a in Children, its Incidence, Presentation, Complications and Outcome: A Study from Eastern India. J Nepal Paediatr Soc 2017;37(3):226-231.

doi: http://dx.doi.org/10.3126/jnps.v37i3.18100

This work is licensed under a Creative Commons Attribution 3.0 License. 
hepatitis in tropical countries like India. The disease is usually mild and self-limiting, and complications are very rare. The clinical picture of viral hepatitis $A$ is extremely variable, ranging from asymptomatic infection to fulminant disease. Nevertheless, hepatitis A can sometimes cause acute liver failure (ALF), a severe, life-threatening condition ${ }^{1}$. Acute liver failure (ALF) is defined by the onset of jaundice, coagulopathy and encephalopathy within eight weeks, in the absence of prior liver disease. ${ }^{2}$

Acute liver failure is an extremely uncommon complication of viral hepatitis A, occurring in $0.1 \%-0.4 \%$ of the paediatric cases ${ }^{3}$. In ALF, massive hepatocellular necrosis takes place, accounting not only for jaundice, coagulopathy and encephalopathy, but also for suggestive laboratory findings, such as markedly high alanine aminotransferase (ALT) blood levels, in contrast to elevations of aspartate aminotransferase (AST) blood levels found under less severe conditions, in which necrosis is not so massive. Adequate management should be done in an intensive care unit, paying special attention to the appearance of potentially deadly complications, like cerebral oedema, digestive bleeding, renal failure and sepsis. In spite of the development of new techniques, ALF mortality rate is above $80 \%$ and in spite of specific therapeutic options in distinctive aetiologies, orthotropic liver transplantation is the only therapy proven to improve patient survival in the majority of patients. The outcome is determined by the complications like severe coagulopathy, infections, renal impairment or increased intracranial pressure. The decision for transplantation depends on the possibility of spontaneous hepatic recovery, which may be estimated by several factors. The most important variables for predicting the need of transplantation in fulminant hepatic failure are the degree of encephalopathy, patient's age and the underlying cause of liver failure. ${ }^{4}$

The objectives of the study were to evaluate the epidemiology, clinical spectrum and laboratory picture of acute viral hepatitis $A$ in children, to analyse the complications of hepatitis $A$ in children and review the mortality and morbidity due to viral hepatitis for better prevention in south East Asia.

\section{Materials and Methods}

It was a prospective study, done in Department of paediatrics, Maharaja Krushna Chandra Gajapati, Berhampur, Odisha, India from May 2014-April 2016. The cases were diagnosed on basis of meticulous history and examination, liver function tests and tests for viral markers in all selected cases. Informed consent was taken. Ethical clearance was obtained from ethical committee of MKCG Medical College. The study group included patients having the following conditions: History or features of prodromal symptoms like fever, nausea, vomiting, anorexia, yellowish discoloration of urine and body, pain abdomen, change in mental status and coagulopathy with suspicion of acute hepatitis (within eight weeks) with positive IgM for hepatitis A.

Following patients were excluded from the study

a. History suggesting pre-existing liver disease, exposure to hepatotoxic drug or toxin, positive $\mathrm{HbSAg}$, presence of isolated viral markers of nonhepatitis A origin were excluded.

b. All patients with diseases like malarial hepatitis, haemolytic anaemia, neonatal/obstructive jaundice were excluded.

c. Patients who went out of the hospital without medical advice.

d. Patients with more than 14 years of age.

The cases were investigated for routine CBC, LFT, serum protein and albumin, serum urea and creatinine, serum electrolytes, random blood glucose (RBS), urine routine and microscopy, urine bile salt and bile pigment, blood and urine culture and sensitivity, x-ray chest, ultrasonography of abdomen and pelvis andHbSAg on the day of admission. The serum electrolytes and RBS were done on daily basis and average values were taken. Serological tests were done to rule out non hepatitis A viral hepatitis on second day of hospitalisation. Ultrasonography and liver biopsy were done when needed to establish the diagnosis. Immunochromatographic test for malarial antigen, Widal test, sickling, HPLC was done to rule out other causes of jaundice.

Statistical analysis was done by SPSS Software version 20. $p$-value $<0.05$ was taken to be significant.

\section{Results}

Total number of patients were $80(n=80)$. The most common age group was $5-9$ years $(45 \%)$ followed by $0-4$ years $(42.5 \%)$. The youngest patient was 10 months and the mean age of presentation was 5.5 years. All the infants who had been admitted died (tab-1). 1 child from the 5-9 age group succumbed.

In the study group Male consisted of $43 \%$ and female $57 \%$ (M:F=1:1.32) Among 3 patients died, 2 were below 1 year. They delayed hospitalization depending on local herbal remedies.

\section{Presentation}

Most common presenting symptom was jaundice in $90.1 \%$. Rest cases were anicteric. Fever was present 
Table 1: Age demography

\begin{tabular}{lccc}
\hline Age in years & Total patients (No. \& \%) & Survivor & Death \\
\hline $0-4$ & $34(42.5 \%)$ & $32(40 \%)$ & $2(2.5 \%)$ \\
\hline $5-9$ & $36(45 \%)$ & $35(43.75 \%)$ & $1(1.25 \%)$ \\
\hline $10-14$ & $10(12.5 \%)$ & $10(12.5 \%)$ & 0 \\
\hline Total & $\mathbf{8 0}$ & $\mathbf{7 7 ( 9 6 . 2 5 \% )}$ & $\mathbf{3}(\mathbf{3 . 7 5} \%)$ \\
\hline Mean age: 5.5 years & & & \\
\hline
\end{tabular}

Table 2: Investigations

\begin{tabular}{lcccc}
\hline Parameters & $\mathbf{0 - 4}$ year (34) & $\mathbf{5 - 9}$ year (36) & $\mathbf{1 0 - 1 4}$ yr (10) & Total \\
\hline Low TPC & 5 & 5 & 2 & $12(15 \%)$ \\
\hline High/Low TLC & 30 & 30 & 8 & $68(85 \%)$ \\
\hline Sr. Bil total & 27 & 36 & 9 & $72(90 \%)$ \\
\hline Sr. Bil direct & 27 & 36 & 9 & $72(90 \%)$ \\
\hline ALT & 28 & 31 & 9 & $68(85 \%)$ \\
\hline AST & 24 & 27 & 5 & $56(70 \%)$ \\
\hline ALP & 20 & 22 & 2 & $44(55 \%)$ \\
\hline PT & 8 & 6 & 4 & $18(22 \%)$ \\
\hline Albumin & 8 & 3 & 1 & $12(15 \%)$ \\
\hline USG (hepatomegaly) & 32 & 34 & 10 & $76(95 \%)$ \\
\hline USG (splenomegaly) & 18 & 10 & 3 & $31(37 \%)$ \\
\hline USG (both) & 18 & 10 & 3 & $31(37 \%)$ \\
\hline RBS (Pre-Treatment) & 30 & 28 & 8 & $66(83 \%)$ \\
\hline
\end{tabular}

Table 3: Complications

\begin{tabular}{lcccc}
\hline Complications & $\mathbf{0 - 4}$ Year (34) & $\mathbf{5 - 9}$ Year (36) & $\mathbf{1 0 - 1 4}$ Year (10) & Total \\
\hline Coagulopathy & 8 & 6 & 4 & 18 \\
\hline Thrombocytopenia & 5 & 5 & 2 & 12 \\
\hline Ascites & 21 & 6 & 3 & 30 \\
\hline GB wall thickening & 22 & 12 & 2 & 36 \\
\hline Pleural effusion & 8 & 2 & 0 & 12 \\
\hline ARF & 1 & 0 & 0 & 1 \\
\hline AGN & 1 & 0 & 0 & 1 \\
\hline Pancreatitis & 1 & 0 & 0 & 2 \\
\hline Cholestasis & 2 & 0 & 1 & 5 \\
\hline CHF & 3 & 1 & 0 & 3 \\
\hline Encephalopathy & 2 & 1 & & \\
\hline
\end{tabular}

in $69(80.6 \%)$, followed by other prodromal symptoms like pain abdomen, nausea, vomiting, dyspepsia and anorexia. Commonest sign was hepatomegaly in $95 \%$ followed by icterus in $90 \%$ cases. The other signs were splenomegaly in 31(38\%), altered sensorium, bleeding, ascites.

\section{Laboratory parameters}

The lab parameters were analysed. The normal reference range of total and direct bilirubin was 0.2 $1.2 \mathrm{mg} / \mathrm{dL}$ and $0.1-0.4 \mathrm{mg} / \mathrm{dL}$ respectively. More than five fold rise in Aspartate transaminase (AST) and
Alaninetransaminase (ALT), i.e > $200 \mathrm{IU} / \mathrm{dl}$ were taken as significant. Similarly for Prothrombin time, INR > 1.5, TLC $>11000 / \mathrm{mm} 3 /<5000 / \mathrm{mm} 3$, TPC $<1$ lakh/mm3, Serum albumin $<35 \mathrm{~g} / \mathrm{L}$, Alkaline phosphatase $>350$ IU/L \& random blood sugar $<54 \mathrm{mg} / \mathrm{dl}$ were taken as significant for the study (table-2).

\section{Complications}

Coagulopathy (Prothrombin time INR $>1.5$ ) was observed in $18(22.5 \%)$ cases and abnormal aPTT in $12(15 \%)$ cases. Thrombocytopenia was observed in $15 \%$ of children and $10(12.5 \%)$ had more than two 
haematological abnormalities. Ascitis was noted in $30(37.5 \%)$ cases, gallbladder wall thickening in $36(45 \%)$ cases and pleural effusion in $12(15 \%)$ cases. Acute renal failure, acute glomerulonephritis and acute pancreatitis were present in one case each. Raised CK-MB values more than three times the normal was noted in five cases. On follow up, most of the children recovered completely by two months and prolonged cholestasis was observed in two of them. In the present study mortality was $3.7 \%$ and it was attributable to fulminant hepatic failure (Table-3).

\section{Discussion}

In many previous studies it is apparent that hepatitis $A$ is a common organism causing fulminant hepatic failure. ${ }^{5}$ Severity is high in extremities of age. It holds true in our study. All the infants presented with liver failure due to hepatitis A died. In post infancy age total number of deaths in the study cohort is 1 . The mean age of presentation was 5.5 years. All those died had come to hospital after one week of incidence of jaundice. The high incidence of death can be explained by delay in treatment and immaturity of liver. Although viral hepatitis $A$ is usually a mild, self-limited disease, high mortality rates for ALF in children and adolescents stress the need of early identification of patients who present severe evolution. The risk of fulminant hepatitis ranges from 0.015 to $0.5 \%$, and the highest rates occur among young children and older adults with underlying chronic liver disease. Aiming at that identification, several prognostic criteria adopted in the management of patients with a poor evolution have been discussed. . $^{6,7,8}$

Infection by HAV is generally self-limited and can produce effects that range from a lack of symptoms to death from fulminant hepatitis. In present study most common presentation was jaundice. In lower age group like $<4$ years jaundice is not so evident. Other common features were fever, tender hepatomegaly, fatigue etc. In several other studies in developing countries where wide vaccination of hepatitis $A$ is not so common the prevalence of viral hepatitis is high and they are icteric mostly in preschool and school going children ${ }^{8,9}$. As it is a highly hepatotropic virus involvement of liver gives rise to observable jaundice ${ }^{10,11}$. The likelihood of clinically apparent disease associated with HAV infection increases with age. In very young age, most infections (70\%) are asymptomatic, and if illness does occur, it is usually anicteric, this leads to delayed diagnosis. Among older children infection is usually symptomatic, with jaundice occurring in> $70 \%$ of patients ${ }^{12}$. After an average incubation period of 28 days (range, 15 to 50 days), most HAV-infected persons developed nonspecific constitutional signs and symptoms followed by gastrointestinal symptoms. Typically, these include fever, malaise, anorexia, nausea, abdominal discomfort, dark urine, and jaundice, all of which usually last $<2$ months. However, 15 to $20 \%$ of the patients may have prolonged or relapsing disease lasting up to 6 months ${ }^{13}$.

Low TPC was observed in $15 \%$ where as high or low TLC was evident in $85 \%$ of patients. As it's a viral infection lymphocytosis was more predominant. In some cases leucocytopenia was also observed. Thrombocytopenia is also seen in hepatitis A infection. It is not so common. But it can be explained by the autoimmune feature of viral hepatitis. The pathogenesis of thrombocytopenia has been postulated to be caused as a result of deposition of immune complexes on the platelet surface or to the development of anticardiolipin antibodies $^{14}$. Bilirubin was high in $90 \%$ of patients. Lesser age group were more anicteric as stated by studies described above. Alteration in hepatic enzymes were much more common finding. In $85 \%$ of cases ALT was high whereas AST was high in $70 \%$ of cases and ALP was high in $55 \%$ of patients. Patients with a marked increase in aminotransferase levels ( $>10$ times the upper reference limit) typically have acute hepatic injury. In cases of acute viral hepatitis, aminotransferase levels usually peak before jaundice appears and have a more gradual decrease thereafter, and there is a greater increase in serum bilirubin levels ${ }^{[15]}$. This explains why we didn't find raised liver enzymes in some patients. Both aminotransferases are highly concentrated in the liver. AST is also diffusely represented in other organs like heart, skeletal muscle, kidneys, brain and red blood cells, and ALT has low concentrations in skeletal muscle and kidney an increase in ALT serum levels is, therefore, more specific for liver damage ${ }^{[16]}$. This explains rise in ALT is found in more numbers of patients. However, when it is certain that the cause of their alteration is liver disease, serum albumin levels and prothrombin time are useful tests for monitoring liver synthetic activity. $22 \%$ of the study group were having increase in PT and $15 \%$ were having alteration in albumin concentrations. Hypoglycemia was observed in $83 \%$ of patients. It is commonly seen due to inadequate glycogenolysis and neoglucogenesis in the liver ${ }^{17}$.

$95 \%$ of patients were having hepatomegaly. Sonography is often the first imaging procedure performed in the evaluation of individuals with suspected liver disease. Sonography is of limited usefulness in acute hepatitis. Ultrasound plays an important role in the imaging of conditions and procedures common in patients with diffuse liver disease ${ }^{18}$.

Most common complication was gall bladder wall thickening. It was observed in $45 \%$ of cases. It 
was detected in serial sonography in follow up after discharge. Collapsed gall bladder with increased wall thickness and pericholecystic oedema were most consistent finding. One hypothesis is that gallbladder wall thickening, together with a decrease in gallbladder volume, occurs when hepatocyte injury at the time of onset of acute hepatitis causes a temporary decrease in bile production and excretion. A second hypothesis is that gallbladder wall thickening is due to a direct injury to and inflammation of the mucosal and muscular layers of the gallbladder by hepatitis virus contained in bile juice ${ }^{[19]}$. Other complications like ascitis, pleural effusion, acute glomerulonephropathy, congestive heart failure, and encephalopathy etc were observed. 3 patients died in the course of treatment in the hospital. Similar complications were observed in other studies ${ }^{20}$.

There are very less numbers of Indian studies available to delineate the complications of Hepatitis $A$ in children. However one study published in Indian journal of paediatrics revealed similar complications like our study ${ }^{21}$. The death toll is mildly high in our study it

\section{References}

1. Kliegman RM, Behrman RE, Jenson HB, Stanton BM Nelson Textbook of Pediatrics E-Book. Elsevier Health Sciences; 2007 Aug 15.

2. Squires RH, Shneider BL, Bucuvalas J, Alonso E, Sokol RJ, Narkewicz MR, Dhawan A, Rosenthal P, Rodriguez-Baez N, Murray KF, Horslen S. Acute liver failure in children: the first 348 patients in the pediatric acute liver failure study group. $J$ Pediatr 20061;148(5):652-8.

3. Whitington P.F., Soriano H.E., Alonso E.M. Fulminant Hepatic Failure in Children. In: Suchy F.J., Sokol R.J., Balistreri W.F., eds. Liver Disease in Children. Lippincott Williams \& Wilkins 2001:63-88

4. Bernal W, Auzinger G, Dhawan A, Wendon J. Acute liver failure. Lancet 2010;376(9736):190-201. DOI: https://doi.org/10.1016/S0140-6736(10)60274-7

5. Lee WS, McKiernan P, Kelly DA. Etiology, outcome and prognostic indicators of childhood fulminant hepatic failure in the United Kingdom. I Pediatr Gastroenterol Nutr 2005;40(5):575-81. 10.1097/01. MPG.0000158524.30294.E2

6. Dhiman RK, Jain S, Maheshwari U, Bhalla A, Sharma $\mathrm{N}$, Ahluwalia J, Duseja A, Chawla Y. Early indicators of prognosis in fulminant hepatic failure: An assessment of the Model for End-Stage Liver Disease (MELD) and King's College Hospital Criteria. Liver Transpl 2007;13(6):814-21. DOI: 10.1002/It.21050

7. Polson J, Lee WM. AASLD position paper: the management of acute liver failure. Hepatology 2005;41(5):1179-97. DOI: 10.1002/hep.20703 may be due to delayed hospitalisation, poor educational standard of people of eastern India and above all the blind belief on magicians etc.

\section{Conclusion}

As south East Asia is a tropical region where the burden of viral hepatitis due to hepatitis $A$ virus infection is very common. Contrasting to common belief every hepatitis a infection is not always benign. It may cause coagulopathy, ascitis, thrombocytopenia, pleural effusion. Even it can cause mortality due to fulminant liver failure. The complications are more common in younger age group. Physicians all over this region should be aware of these features of hepatitis $A$ because in small children it's not so evident always. All cases should be followed up till complete recovery and only a strong index of suspicion will enable us to recognize the complications. This study will raise the consciousness of urgency of vaccination for hepatitis $A$, which is thought to be sparingly optional for many parents as well as doctors.

8. Romero R, Lavine JE. Viral hepatitis in children. In Seminars in liver disease 1994 Aug (Vol. 14, No. 03, pp. 289-302). (c) 1994 by Thieme Medical Publishers, Inc.

9. Kelly D. Viral hepatitis in children. In Hot Topics in Infection and Immunity in Children 2004 (pp. 83-90). Springer, Boston, MA.

10. Nel E, Sokol RJ, Comparcola D, Nobili V, Hardikar W, Gana JC, Abarca K, Wu JF, Chang MH, Renner JK. Viral hepatitis in children. J Pediatric Gastroenterol Nutr 2012;55(5):500-5. DOI: 10.1097/ MPG.0b013e318272aee7

11. Cuthbert JA. Hepatitis A: old and new. Clin Microbiol $\operatorname{Rev} 2001 ; 14(1): 38-58$. DOI: 10.1128/CMR.14.1.3858.2001

12. Gilgen, M., D. Germann, J. Luthy, and P. Hubner. Threestep isolation method for sensitive detection of enterovirus, rotavirus, hepatitis A virus, and small round structured viruses in water samples. Int $J$ Food Microbiol 1997;37:189-199. DOI: https://doi. org/10.1016/S0168-1605(97)00075-5

13. Centers for Disease Control and Prevention. 1996. Hepatitis surveillance report no. 56. U.S. Department of Health and Human Services, Public Health Service, CDC, Atlanta, Ga. (Available at http://www.cdc.gov/ nciod/diseases/hepatitis/h96surve.htm. Accessed 1 September 1998.)

14. Ertem D, Acar Y, Arat C, Pehlivanoglu. Thrombotic and thrombocytopenic complications secondary to hepatitis A infection in children. Am J Gastroenterol 1999;94:3653-655. DOI:10.1111/j.15720241.1999.01627.x 
15. Giannini EG, Testa R, Savarino V. Liver enzyme alteration: a guide for clinicians. Can Med Assoc J 2005;172(3):367-79. DOI:10.1503/cmaj.1040752

16. Botros M, Sikaris KA. The de ritis ratio: the test of time. Clin Biochem Rev 2013;34(3):117. DOI: 10.5455/ ijmsph.2016.24122015322

17. Chandra RK, Newberne PM. Nutrition, immunity, and infection: mechanisms of interactions. Springer Science \& Business Media; 2012 Dec 6.

18. Tchelepi H, Ralls PW, Radin R, Grant E. Sonography of diffuse liver disease. J Ultrasound Med 2002;21(9): 1023-32. DOI: 10.7863/jum.2002.21.9.1023

19. Suk KT, Kim CH, Baik SK, Kim MY, Park DH, Kim KH, Kim JW, Kim HS, Kwon SO, Lee DK, Han KH.
Gallbladder wall thickening in patients with acute hepatitis. J Clin Ultrasound 2009;37(3):144-8. DOI: $10.1002 /$ jcu.20542

20. Detry, Oliver, et al., "Brain Edema and Intracranial Hypertension in Fulminant Hepatic Failure: Pathophysiology and Management," World J Gastroenterol 2006;12(46):7405-412. DOI: 10.3748/ wjg.v12.i46.7405

21. Kumar, KJ, Kumar, HCK, Manjunath VG. Anitha C, Mamatha S. Hepatitis A in Children- Clinical Course, Complications and Laboratory Profile. Indian J Pediatr 2014;81:15. DOI: https://doi.org/10.1007/s12098-013$1114-8$ 